\title{
Calorie Restriction the Fountain of Youth
}

\author{
Bashir Ahmed Dar ${ }^{1 *}$, Manzoor Ahmed Dar ${ }^{2}$, Sheeba Bashir ${ }^{3}$ \\ ${ }^{1}$ Department of Medicine, Melaka Manipal Medical College, Melaka, Malaysia; ${ }^{2}$ Department of Surgery, Sohar Hospital Oman, So- \\ har, Oman; ${ }^{3}$ Department of Pathology, Acharya Shri Chander College of Medical Sciences \& Hospital (ASCOMS), Jammu, India. \\ Email: *drbashir123@gmail.com,drmadar@hotmail.com,drsheeba98@gmail.com
}

Received August 29 $9^{\text {th }}, 2012$; revised September 29 $9^{\text {th }}, 2012$; accepted October $7^{\text {th }}, 2012$

\begin{abstract}
Calorie restriction (CR) is as close to a real fountain of youth as any known technique is. Caloric restriction known to extend the human lifespan by up to five years has quietly become accepted among leading researchers. Even scientists who are cautious about anti-aging hype say it works. The formula is simple: Eat less. It could add years to your life. In the context of health and longevity, I analyzed data documenting proofs which suggest that the caloric restriction extends life span and retards age-related chronic diseases in a variety of species, including rats, mice, fish, flies, worms, and yeast as well as improve biomarkers of aging in humans. Research has shown that not only does it result in a longer lifespan, but it also lowers blood pressure, oxidative damage, cardiovascular disease, modifies insulin sensitivity, reduces loss of central nervous system cells, strengthens the immune system, lowers cholesterol, diminishes the rate of heart disease, reduces muscle oxygen loss, improves muscle function, reduces free radical damage to body tissue and helps stabilize blood sugar in adult-onset diabetes. Caloric restriction the most widely recognized life span-extending intervention has shown that it does indeed have age-slowing effects in humans like it has been shown to work in animals and Dr. Fontana has already made medical history in studying anti aging effects of caloric restriction.
\end{abstract}

Keywords: Anti Aging; Longevity Technique; Everlasting Youth; Evergreen Youth; Elixir of Life

\section{Introduction}

As we grow old our mind and body gradually degrade, losing the vigor and resulting in a wide range of effects. Memory is weakened, motor skills decline, bones become brittle, and skin loses elasticity and leads to increased susceptibility to infection and disease partly because of the decline of the immune system.

There has been a search throughout human history for key to eternal life and numerous researches have been done in an attempt to extend life. The age-old quest for the antidote to aging has moved into scientific labs. Everyone seems now concerned about the quality and safety of life besieged by pollution, indifferent foods and sedentary living. No one seems to have an answer as to how best one can lead a good quality life with extended longevity.

Medical science is making significant progress in understanding the riddle of what happens when we ageand evaluating techniques, which can slow or even reverse the process. Today, evidence is accumulating that to live longer is to eat less.

Hundreds of scientific research studies clearly prove that modest interventions in diet, exercise, and nutrition and single-gene modulation in the laboratory setting

\footnotetext{
*Corresponding author.
}

beneficially and significantly improve health in old age and prolong life.

The idea of lowering food intake is not a new one. Several religions like Islamic Ramadan, the three princepal fasting periods of Greek Orthodox Christianity and the Biblical-based Daniel Fast advocate food restrictions [1]. These religious fastings on which scholarly research has been performed have noted favorable changes in biomarkers of good quality of life and longevity. Researchers also confirm now that one of the important techniques to prolong life is by caloric restriction as seen in variety of organisms, including yeast, insects, rats, mice, and monkeys.

\section{Caloric Restriction (CR)}

The basic idea of CR is that you can live much longer if you design a diet for yourself which is low in calories, but provides all of the necessary nutrition. Calorie restriction with Optimum nutrition (CRON), also called the Longevity Diet, has the potential to increase the average and maximum life span by under nutrition but without malnutrition. Optimum Nutrition consists of eating the right amounts of nutrients on a proper schedule to achieve the best performance and good health. Calorie restriction is a feature of several dietary regimens, in- 
cluding the Okinawa diet [2,3] and the CRON-diet.

Whereas CR is a reduction of caloric intake, Dietary Restriction (DR) is a specific reduction/manipulation in nutrient intake. DR need not necessarily result in CR, because the reduced intake of a particular nutrient (typically a macronutrient) may be offset by an increased intake of one or more other nutrients. Some researchers estimate that energy consumption must be reduced by a minimum of $20 \%$ - $25 \%$ in order to beget any life-extending benefits from a CR regimen [4-6].

Louis Caranaro's 16th century best-selling anti-aging book suggested that longevity would come to those who ate only enough to sustain life. Two centuries later Benjamin Franklin supported the concept of abstinence as a defense against disease.

It was the work of McCay in the 1930 that first demonstrated that reducing calories could extend the mean and maximum lifespan of laboratory rats by $40 \%$ or more [7].

McCay CM, et al., discovered that reducing the amount of calories fed to rodents nearly doubled their lifespan. The life extension was varied for each species but on average, there was a $30 \%-40 \%$ increase in lifespan in both mice and rats.

Research in 2003 by Mair et al., showed that calorie restriction extends the life of fruit flies of any age with instantaneous effects on death rates [8].

Results from the ongoing calorie-restriction studies in monkeys also suggest that the mortality rate in calorierestricted animals will be lower than that in control subjects [9]. Furthermore, calorie-restricted monkeys have lower body temperatures and insulin concentrations than do control monkeys and both of these variables are biomarkers for longevity.

Calorie-restricted monkeys also have higher concentrations of dehydroepiandrosterone sulfate. The importance of dehydroepiandrosterone sulfate is not yet known, but it is suspected to be a marker of longevity in humans [10], although this is not observed consistently.

Results published in 2009 showed that caloric restricttion in rhesus monkeys blunts aging and significantly delays the onset of age related disorders such as cancer, diabetes, cardiovascular disease and brain atrophy. 80\% of the calorically restricted monkeys were still alive, compared to only half of the controls [11].

The relevance of CR life span prolonging effects for primates was explored in a 20-year longitudinal adultonset CR study in rhesus monkeys. The animals' baseline intake of calories was reduced progressively by $10 \%$ per month to a final $30 \%$ reduction that was maintained for the duration of the experiment. The effect of CR, compared to control, was evaluated by comparing the delay in mortality and the onset of some age-associated conditions most prevalent in humans (e.g. diabetes, cancer, cardiovascular disease, and brain atrophy). The conclusions of the study were that CR lowered the incidence of aging-related deaths (50\% in control fed animals versus $20 \%$ in CR-fed animals) and also lowered the incidence of diabetes, cancer, cardiovascular disease, and brain atrophy [12].

Ideally, CR should be started after the body has matured and stopped growing because low calorie diets may stunt growth even when the diet contains all essential nutrients. It is also not advisable to practice CR during pregnancy or illness, as at these times the body needs adequate nutrition for the proper formation of a fetus or to fight disease.

Adult-onset CR works best when it is imposed slowly to allow the body to adjust. The calories should be reduced gradually during a period of two or three years, rather than suddenly.

The chances of survival are increased just by maintaining a lean body. Experiments with rhesus monkeys have shown that those restricted to keep their body fat at approximately 17 to 24 percent had a 2.6 lower risk of death than non-restricted monkeys [13].

In one study, rats and mice ate a low-calorie diet or were deprived of food for 24 hours every other day. [14] This methods improved glucose metabolism, increased insulin sensitivity, and increased stress resistance. Researchers have long been aware that calorie restriction extends lifespan, but this study showed that improved glucose metabolism also protects neurons in experimenttal models of Parkinson's and stroke.

Thus CR has been proved consistently in species as diverse as fruit flies [15], guppies [16], and dogs [17], to increase longevity. Also, CR reduces the morbidity caused by diseases, including autoimmune diseases, atherosclerosis, cardiomyopathies, cancer, diabetes, renal diseases, neurodegenerative diseases, and respiratory diseases.

It is not so easy to definitively answer whether or not CR prolongs human life because of the ethical and logistical limitations of research design. Most human CR studies measure biomarkers correlated with longevity. Collectively, these studies have noted favorable changes in multifarious biomarkers, particularly those related to cardiovascular and glucoregulatory function in humans.

Most animal CR studies begin the restriction of calories during the weaning phase and continue throughout the subject's lifespan. Obviously, no human study has ever initiated CR that early or for that long a duration. Instead, CR is typically instituted for a period of $6-12$ months [18]. However, a few studies have examined CR for 2 years [19], 6 years [20,21], and longer in humans [22].

The majority of work has been conducted on healthy, middle aged, non-obese (normal or overweight) men and women, with a significant amount of investigations util- 
izing data obtained from the CALERIE (Comprehensive Assessment of Long Term Effects of Reducing Caloric Intake) program $[23,24]$.This program was initiated by the National Institute on Aging to investigate the adaptive responses of CR on free-living humans $[25,26]$.

In addition to the CALERIE program, another investigation of importance, Biosphere 2, contained eight subjects aged from 27 - 67 years [27]. These subjects lived in an enclosed $\sim 3$ acre "ecological mini-world" for two years. Food intake was subnormal due to the inability to grow enough food for ad libitum consumption; hence, subjects followed a CR plan by default. Aside from normal weight men and women, investigations involving $C R$ has also included obese, diabetic, young, and elderly individuals [28-31].

Numerous such above studies have found that CR improves cardiovascular and glucoregulatory health in humans. Specifically, CR may reduce the risk of cardiovascular disease by lowering total cholesterol, triglycerides, blood pressure, and carotid intima-media thickness [32,33].

CR also has been shown to attenuate the age-related decline in diastolic function in humans. Glucoregulatory health, circulating insulin and glucose levels decrease in humans-while insulin sensitivity increases_following a period of CR [34-37].

CR has also been shown to attenuate oxidative stress in humans [38] a condition thought to contribute to aging and disease. In addition, enhanced verbal memory performance has been reported in elderly individuals on a CR regimen as assessed by the Rey Auditory Verbal Learning Task [39].

\section{Conclusions}

Caloric restriction has been the subject of intense research that has begun to bear the fruit, steady stream of these studies are now revealing that the rate of aging is plastic and not fixed, and that it can be manipulated. We now know by above studies that caloric restricted animals have a longer life expectancy than average. The goal is not just to make people live longer but to see eventually that an 80-year-old feels like a 50-year-old.

The calorie restriction (CR) is now the most widely recognized life span-extending intervention in all varieties of animals, including various mammalian species. Such studies facilitate the development of novel approaches to extend the lifespan of humans. Plenty of evidence has been provided by such studies that show it can reduce your risks for many common diseases including cancer, diabetes and heart disease.

Caloric restriction suggests ways to not just make us live longer, but to allow us to age more gracefully, healthwise. Perhaps even more promising, though in early stages of research, are drugs designed on the basis of what's been learned from calorie-restriction studies and that day is not too far when anti-aging pill will be the next big blockbuster so that appointments with death are postponed.

\section{Author's Contributions}

Author 1: Involved in planning the article, writing of the article, editing, critical analysis, final drafting and final approval of the article.

Author 2: involved in editing, critical analysis, final drafting and final approval of the article.

Author 3: involved in editing, critical analysis, final drafting and final approval of the article.

\section{REFERENCES}

[1] K. O. Sarri, S. Higgins and A. G. Kafatos, “Are Religions Healthy? A Review on Religious Recommendations on Diet and Lifestyle,” Human Ecology, Vol. 14, 2006, pp. 7-20.

[2] R. L. Walford and L. Walford, "Anti-Aging Plan Strategies and Recipes for Extending Your Healthy Years," Publisher Four Walls Eight Windows, New York, 1995, p. 26

[3] B. J. Willcox, D. G. Willcox, H. Todoriki, A. Fujiyoshi, K. Yano, Q. M. He, J. D. Curb and M. Suzuki, "Caloric Restriction the Traditional Okinawan Diet and Healthy Aging the Diet of the World's Longest-Lived People and Its Potential Impact on Morbidity and Life Span,” Annals of the New York Academy of Sciences, Vol. 1114, 2007, pp. 434-455.

http://onlinelibrary.wiley.com/doi/10.1196/annals.1396.0 37/abstract

doi:10.1196/annals.1396.037

[4] K. P. Keenan, G. C. Ballam, R. Dixit, K. A. Soper, P. Laroque, B. A. Mattson, S. P. Adams and J. B. Coleman, "The Effects of Diet Overfeeding and Moderate Dietary Restriction on Sprague-Dawley Rat Survival Disease and Toxicology,” Journal of Nutrition, Vol. 127, No. 5, 1997, pp. 851S-856S.

[5] M. F. Hubert, P. Laroque, J.-P. Gillet and K. P. Keenan, "The Effects of Diet ad Libitum Feeding And Moderate and Severe Dietary Restriction on Body Weight Survival Clinical Pathology Parameters and Cause of Death in Control Sprague-Dawley Rats,” Journal of Toxicol Science, Vol. 58, No. 1, 2000, pp. 195-207. doi:10.1093/toxsci/58.1.195

[6] Z. Djuric, S. M. Lewis, M. H. Lu, M. Mayhugh, L. Naegeli, N. Tang and R. W. Hart, "Effect of Varying Caloric Restriction Levels on Female Rat Growth and 5-Hydroxymethyl-2'-deoxyuridine in DNA," Toxicological Science, Vol. 66, No. 1, 2002, pp. 125-130.

doi:10.1093/toxsci/66.1.125

[7] C. M. McCay, M. F. Crowell and L. A. Maynard, "The Effect of Retarded Growth upon the Length of Life Span and upon the Ultimate Body Size,” Journal of Nutrition, Vol. 10 No. 1, 1935, pp. 63-79. 
[8] W. Mair, P. Goymer, S. D. Pletcher and L. Partridge, "Demography of Dietary Restriction and Death in Drosophila,” Science, Vol. 301, No. 5640, 2003, pp. 17311733. doi:10.1126/science.1086016

[9] J. W. Kemnitz, R. Weindruch, E. B. Roecker, K. Crawford, P. L. Kaufman and W. B. Ershler, "Dietary Restriction of Adult Male Rhesus Monkeys Design Methodology and Preliminary Findings from the First Year of Study," Journal of Gerontology, Vol. 48, No. 1, 1993, pp. B17B26.

http://geronj.oxfordjournals.org/content/48/1/B17.short

[10] G. Ravaglia, P. Forti, F. Maioli, L. Sacchetti, V. Nativio, C. R. Scali, E. Mariani, V. Zanardi, A. Stefanini, P. Macini, "Dehydroepiandrosterone-Sulfate Serum Levels and Common Age Related Diseases Results from a Cross-Sectional Italian Study of a General Elderly Population,” Experimental Gerontology, Vol. 37, No. 5, 2002, pp. 701-712. doi:10.1016/S0531-5565(01)00232-7

[11] N. Wade, "Dieting Monkeys Offer Hope for Living Longer,” The New York Times, 9 July 2009.

[12] R. J. Colman, R. M. Anderson, S. C. Johnson, E. K. Kastman, K. J. Kosmatka,T. M. Beasley, D. B. Allison, C. Cruzen, H. A. Simmons, J. W. Kemnitz and Richard Weindruch, "Caloric Restriction Delays Disease Onset and Mortality in Rhesus Monkeys,” Science, Vol. 325, No. 5937, 2009, pp. 201-204. doi:10.1126/science.1173635

[13] N. L. Bodkin , T. M. Alexander , H. K. Ortmeyer , E. Johnson and B. C. Hansen, "Mortality and Morbidity in Laboratory-Maintained Rhesus Monkeys and Effects of Long-Term Dietary Restriction,” Journal of Gerontology: Biological Sciences, Vol. 58, No. 3, 2003, pp. B212-B219. doi:10.1093/gerona/58.3.B212

[14] R. M. Anson, Z. H. Guo, R. de Cabo, T. Iyun, M. Rios, A. Hagepanos, D. K. Ingram, M. A. Lane and M. P. Mattson, "Intermittent Fasting Dissociates Beneficial Effects of Dietary Restriction on Glucose Metabolism and Neuronal Resistance to Injury from Calorie Intake,” Proceedings of the National Academy of Sciences, Vol. 100, No. 10, 2003, pp. 6216-6220.

[15] K. J. Min, T. Flatt, I. Kulaots and M. Tatar, "Counting Calories in Drosophila Diet Restriction,” Experimental Gerontology, Vol. 42, No. 3, 2007, pp. 247-251. doi:10.1159/000211216

[16] A. Comfort, "Effect of Delayed and Resumed Growth on the Longevity of a Fish (Lebistes reticulatus, Peters) in Captivity,” Gerontologia, Vol. 8, No. 2-3, 1963, pp. 150-155.

[17] D. F. Lawler, B. T. Larson, J. M. Ballam, G. K. Smith, D. N. Biery, R. H. Evans, E. H. Greeley, M. Segre, H. D. Stowe and R. D. Kealy, "Diet Restriction and Ageing in the Dog: Major Observations over Two Deades,” British Journal of Nutrition, Vol. 99,No. 4, 2008, pp. 793-805. doi:10.1017/S0007114507871686

[18] L. K. Heilbronn, L. de Jonge, M. I. Frisard, J. P. DeLany, D. Enette Larson-Meyer, J. Rood, T. Nguyen, C. K. Martin, J. Volaufova, M. M. Most, F. L. Greenway, S. R. Smith, W. A. Deutsch, D. A. Williamson and E. Ravussin (The Pennington CALERIE Team), "Effect of 6-Month
Calorie Restriction on Biomarkers of Longevity, Metabolic Adaptation, and Oxidative Stress in Overweight Individuals: A Randomized Controlled Trial,” The Journal of the American Medical Association, Vol. 295, No. 13, 2006, pp. 1539-1548

[19] R. B. Verdery and R. L. Walford, "Changes in Plasma Lipids and Lipoproteins in Humans during a 2-Year Period of Dietary Restriction in Biosphere 2," Archives of Internal Medicine, Vol. 158, No. 8, 1998, pp. 900-906.

[20] R. L. Walford, D. Mock, T. MacCallum and J. L. Laseter, "Physiologic Changes in Humans Subjected to Severe Selective Calorie Restriction for Two Years in Biosphere 2 Health Aging and Toxicological Perspectives," Oxford Journals, Life Sciences \& Medicine, Toxicological Sciences, Vol. 52, Suppl. 1, 1999, pp. 61-65. doi:10.1093/toxsci/52.suppl 1.61

[21] B. J. Willcox, D. Graig Willcox, H. Todoriki, A. Fujiyoshi, K. Yano, Q. M. He, J. D. Curb and M. Suzuki, "Caloric Restriction the Traditional Okinawan Diet and Healthy Aging the Diet of the World's Longest-Lived People and Its Potential Impact on Morbidity and Life Span,” Annals of the New York Academy of Sciences, Vol. 1114, 2007, pp. 434-455. doi:10.1196/annals.1396.037

[22] L. K. Heilbronn, L. de Jonge, M. I. Frisard, J. P. DeLany, D. E. Larson-Meyer, J. Rood, T. Nguyen, C. K. Martin, J. Volaufova, M. M. Most, F. L. Greenway, S. R. Smith, W. A. Deutsch, D. A. Williamson and E. Ravussin (The Pennington CALERIE Team), "Effect of 6-Month Calorie Restriction on Biomarkers of Longevity, Metabolic Adaptation, and Oxidative Stress in Overweight Individuals: A Randomized Controlled Trial," The Journal of the American Medical Association, Vol. 295, No. 13, 2006, pp. 1539-1548.

[23] E. P. Weiss, S. B. Racette, D. T. Villareal, L. Fontana, K. Steger-May, K. B. Schechtman, S. Klein, J. O. Holloszy and the Washington University School of Medicine CALERIE Group, “Improvements in Glucose Tolerance and Insulin Action Induced by Increasing Energy Expenditure or Decreasing Energy Intake: A Randomized Controlled Trial," The American Journal of Clinical Nutrition, Vol. 84, No. 5, 2006, pp. 1033-1042

[24] J. O. Holloszya and L. Fontana, "Caloric Restriction in Humans,” Experimental Gerontology, Vol. 42, No. 8, 2007, pp. 709-712. doi:10.1016/j.exger.2007.03.009

[25] R. L Walford, D. Mock, T. MacCallum and J. L. Laseter, "Physiologic Changes in Humans Subjected to Severe Selective Calorie Restriction for Two Years in Biosphere 2 Health, Aging and Toxicological Perspectives," Oxford Journals Life Sciences \& Medicine Toxicological Sciences, Vol. 52, Suppl. 1, 1999, pp. 61-65.

[26] R. L. Walford, D. Mock, R. Verdery and T. MacCallum, "Alterations in Physiologic Hematologic Hormonal and Biochemical Parameters in Humans Restricted for a 2-Year Period,” Oxford Journals Life Sciences \& Medicine, the Journals of Gerontology 2002, Series A, Vol. 57, No. 6, 2202, pp. B211-B224.

[27] A. B. Crujeiras, D. Parra, I. Abete and J. Alfredo Martínez, "A Hypocaloric Diet Enriched in Legumes Specifically Mitigates Lipid Peroxidation in Obese Subjects," 
Free Radical Research, Vol. 41, No. 4, 2007, pp. 498-506. doi:10.1080/10715760601131935

[28] A. B. Crujeiras, D. Parra, E. Goyenechea, I. Abete and J. Alfredo Martínez, “Tachyphylaxis Effects on Postprandial Oxidative Stress and Mitochondrial Related Gene Expression in Overweight Subjects after a Period of Energy Restriction,” European Journal of Nutrition, Vol. 48, No. 6, 2009, pp. 341-347.

[29] P. Dandona, P. Mohanty, H. Ghanim, A. Aljada, R. Browne, W. Hamouda, A. Prabhala, A. Afzal and Rajesh Garg, "The Suppressive Effect of Dietary Restriction and Weight Loss in the Obese on the Generation of Reactive Oxygen Species by Leukocytes, Lipid Peroxidation, and Protein Carbonylation," The Journal of Clinical Endocrinology \& Metabolism, Vol. 86, No. 1, 2001, pp. 355362. doi:10.1210/jc.86.1.355

[30] J. Skrha, M. Kunesova, J. Hilgertova, H. Weiserova, J. Krizova and E. Kotrlikova, "Short Term Very Low Calorie Diet Reduces Oxidative Stress in Obese Type 2 Diabetic Patients,” Physiological Research, Vol. 54, No. 1, 2005, pp. 33-39.

[31] M. Lefevre, L. M. Redman, L. K. Heilbronn, J. V. Smith, C. K. Martin, J. C. Rood, F. L. Greenway, D. A. Williamson, S. R. Smith and E. Ravussin (the Pennington CA-LERIE Team), "Caloric Restriction Alone and with Exercise Improves CVD Risk in Healthy Non-Obese Individuals," Atherosclerosis, Vol. 203, No. 1, 2009, pp. 206-213. doi:10.1016/j.atherosclerosis.2008.05.036

[32] L. Fontana, T. E. Meyer, S. Klein and J. O. Holloszy, "Long-Term Calorie Restriction is Highly Effective in Reducing the Risk for Atherosclerosis in Humans," Proceedings of the National Academy of sciences of the United States of America, Vol. 101, No. 17, 2004, pp. 6659-6663. doi:10.1073/pnas.0308291101

[33] T. E. Meyer, S. J. Kovács, A. A. Ehsani, S. Klein, J. O. Holloszy and L. Fontana, "Long-Term Caloric Restriction Ameliorates the Decline in Diastolic Function in Humans," Journal of the American College of Cardiology, Vol. 47, No. 2, 2006, pp. 398-402. doi:10.1016/j.jacc.2005.08.069
[34] E. P. Weiss, S. B. Racette, D. T. Villareal, L. Fontana, K. Steger-May, K. B. Schechtman, S. Klein, J. O. Holloszy and the Washington University School of Medicine CALERIE Group, “Improvements in Glucose Tolerance and Insulin Action Induced by Increasing Energy Expenditure or Decreasing Energy Intake a Randomized Controlled Trial," The American Journal of Clinical Nutrition, Vol. 84, No. 5, 2006, pp. 1033-1042.

[35] R. L. Walford, D. Mock, T. MacCallum and J. L. Laseter, "Physiologic Changes in Humans Subjected to Severe Selective Calorie Restriction for Two Years in Biosphere 2 Health Aging and Toxicological Perspectives," Oxford Journals Life Sciences \& Medicine Toxicological Sciences, Vol. 52, Suppl. 1, 1999, pp. 61-65. doi:10.1093/toxsci/52.suppl_1.61

[36] E. P. Weiss, S. B. Racette, D. T. Villareal, L. Fontana, K. Steger-May, K. B. Schechtman, S. Klein, J. O. Holloszy and the Washington University School of Medicine CALERIE Group, “Improvements in Glucose Tolerance and Insulin Action Induced by Increasing Energy Expenditure or Decreasing Energy Intake a Randomized Controlled Trial," The American Journal of Clinical Nutrition, Vol. 84, No. 5, 2006, pp. 1033-1042.

[37] J. Skrha, M. Kunesova, J. Hilgertova, H. Weiserova, J. Krizova and E. Kotrlikova, "Short Term Very Low Calorie Diet Reduces Oxidative Stress in Obese Type 2 Diabetic Patients,” Physiological Research, Vol. 54, No. 1, 2005, pp. 33-39.

[38] P. R. Galassetti, D. Nemet, A. Pescatello, C. RoseGottron, J. Larson and D. M. Cooper, "Exercise Caloric Restriction and Systemic Oxidative Stress," Journal of Investigative Medicine, Vol. 54, No. 2, 2006, pp. 67-75. doi:10.2310/6650.2005.05024

[39] A. V. Wittea, M. Fobkerb, R. Gellnerc, S. Knechta and A. Floelad, "Caloric Restriction Improves Memory in Elderly Humans," Proceedings of the National Academy of Sciences of the United States of America, Vol. 106, No. 4, 2009, pp. 1255-1260.

http://www.pnas.org/content/106/4/1255.full.pdf+html?w ith-ds=yes 